\title{
Medication Adherence in Adolescents with Psychiatric Disorders
}

The Relevance of Demographic and Socioeconomic Factors Plus Parents' Assessments of Their Offspring's Attitudes Towards Treatment

\author{
Clara Both ${ }^{1}$, Konstantin Mechler ${ }^{1}$, Larissa Niemeyer ${ }^{1}$, Christine Jennen-Steinmetz ${ }^{2}$, \\ Sarah Hohmann ${ }^{3}$ Lucca Schumm , Ralf W Dittmann¹, and Alexander Häge ${ }^{1}$ \\ Research Group of Pediatric Psychopharmacology, Department of Child and Adolescent Psychiatry and Psychotherapy, \\ Central Institute of Mental Health, Medical Faculty Mannheim, University of Heidelberg, Mannheim, Germany \\ Department of Biostatistics, Central Institute of Mental Health, Medical Faculty Mannheim, University of Heidelberg, \\ Mannheim, Germany \\ Department of Child and Adolescent Psychiatry and Psychotherapy, Central Institute of Mental Health, Medical Faculty Mannheim, \\ University of Heidelberg, Mannheim, Germany \\ Department of Child and Adolescent Psychiatry and Psychotherapy, Centre for Mental Health, Klinikum Stuttgart, Germany
}

\begin{abstract}
Objective: This study investigates whether adolescents' adherence to psychotropic medication is associated with demographic and socioeconomic factors, and to what extent parents' assessments of their offspring's attitudes toward treatment correspond with the adolescents' self-report. Methods: This study is part of the multicenter SEMA study (Subjective Experience and Medication Adherence in Adolescents with Psychiatric Disorders). Adolescents' subjective attitudes toward medication and their adherence were assessed using the patient and parent versions of the QATT (Questionnaire on Attitudes Toward Treatment) and the MARS (Medication Adherence Rating Scale). Furthermore, we collected socioeconomic and demographic data. Results: Of the $n=75$ adolescents included in the study, $n=45(60 \%)$ were classified as completely adherent. Patients receiving monotherapy were more often completely adherent than those receiving a combination of different medications. There was no statistically significant association between adherence and demographic or socioeconomic factors. Consensus between adolescents and their parents regarding adolescents' attitudes toward treatment ranged from slight $(\mathbf{k}=0.157)$ to fair $(\mathbf{k}=0.205)$. Conclusion: Incomplete medication adherence in adolescents with psychiatric disorders is a common phenomenon and still poorly understood. Demographic and socioeconomic factors do not seem to be relevant in this respect. However, adolescents' subjective attitudes towards medication, which parents are presumably unable to adequately assess, warrant more careful consideration in future research.
\end{abstract}

Keywords: medication adherence, psychotropic medication, adolescence, patient-parent consensus, demographic and socioeconomic factors

Medikamenten-Adhärenz bei Jugendlichen mit psychischen Störungen - Relevanz demografischer und sozioökonomischer Faktoren sowie elterliche Einschätzungen der Einstellungen von Patienten zur Behandlung

Zusammenfassung: Fragestellung: Ziel dieser Studie ist es zu untersuchen, ob adhärentes Verhalten im Rahmen einer Psychopharmakotherapie bei Jugendlichen mit demografischen und sozioökonomischen Faktoren assoziiert ist und inwieweit die elterliche Einschätzung bezüglich der Einstellungen ihrer Kinder zur Medikamenten-Behandlung mit den Angaben der Jugendlichen übereinstimmt. Methodik: Die Studie ist Teil der multizentrischen SEMA-Studie (Subjective Experience and Medication Adherence in Adolescents with Psychiatric Disorders). Subjektive Einstellungen zur Medikation und die Adhärenz von Jugendlichen wurden mithilfe der Patienten- und Elternversion des QATT (Questionnaire on Attitudes Toward Treatment) sowie der MARS (Medication Adherence Rating Scale) beurteilt. Außerdem wurden sozioökonomische und demografische Faktoren erfasst. Ergebnisse: Von $n=75$ Jugendlichen, die in die Studie eingeschlossen werden konnten, wurden $n=45(60 \%)$ als vollständig adhärent eingestuft. Patienten unter Monotherapie waren häufiger vollständig adhärent als Patienten, die eine Kombination verschiedener Medikamente erhielten. Es fand sich kein statistisch signifikanter Zusammenhang zwischen Adhärenz und sozioökonomischen oder demografischen Faktoren. Die Übereinstimmung der Aussagen der Patienten und ihrer Eltern bezüglich der Einstellungen der Jugendlichen zur Medikation war gering ( $k=0,157)$ bis mäßig ( $k=0.205)$ ausgeprägt. Schlussfolgerung: Unvollständige Medikamenten-Adhärenz bei Jugendlichen mit psychischen Störungen ist ein häufiges und bislang unzureichend verstandenes Phänomen. Sozioökonomische und demographische Faktoren scheinen diesbezüglich nicht von Relevanz. Subjektive Einstellungen der Jugendlichen zur Medikation, welche Eltern vermutlich nur unzureichend gut einschätzen können, bedürfen hingegen einer genaueren Betrachtung.

Schlüsselwörter: Medikamenten-Adhärenz, Psychopharmaka, Adoleszenz, Patienten-Eltern Übereinstimmung, demografische und sozioökonomische Faktoren 


\section{Introduction}

Approximately $2.5-9 \%$ of children and adolescents in industrialized nations are diagnosed with a mental disorder, with a slightly higher prevalence in the group of adolescents (Franke et al., 2016; Hsia \& Maclennan, 2009; Kovess et al., 2015; Lopez-Leon et al., 2018; Skaer et al., 2009).

The profound physical and psychological development occurring in adolescence renders it a particularly vulnerable period for mental-health problems, and approximately half of all lifetime psychiatric disorders begin in the midteenage years (Kessler et al., 2007). Sufficient treatment of psychiatric disorders in this population is therefore fundamental to reducing long-term impairment, risk of relapse, socioeconomic costs, and premature mortality (Chapman \& Horne, 2013; Sun et al., 2007). In this respect, adolescents' adherence to treatment - the extent to which a patient follows treatment recommendations - is of utmost importance.

One major cornerstone in the treatment of psychiatric disorders is psychotropic medication, which can help to significantly reduce symptoms and functional impairment and improve patients' quality of life. Rates of children and adolescents being prescribed psychotropic medications have increased over the last decades, with pooled global prevalence rates ranging from $5 \%$ o for antipsychotics and 6\%o for antidepressants, up to $15.3 \%$ o for attention-deficit hyperactivity disorder (ADHD) medication such as psychostimulants (Piovani et al., 2019). However, if patients are unable or unwilling to follow treatment recommendations (i.e., act in a nonadherent way), pharmaceutical treatment approaches remain ineffective.

As adolescents typically have poorer insight into their own functioning, frequently struggle with detachment from parental supervision and individualization, and show more problems with decision-making, they are believed to be more vulnerable in terms of nonadherence compared to children and adults (Brinkman et al., 2016; Buitelaar, 2017; Christie \& Viner, 2005).

Therefore, findings from adherence research in adults and children should not simply be transferred to adolescents. However, research investigating medication adherence in adolescents with psychiatric disorders is limited, and the issue of nonadherence in this age group is insufficiently understood.

Earlier research considered treatment response and safety/tolerability of a medication to be particularly relevant for a patient's medication adherence (Charach \& Fernandez, 2013; Gajria et al., 2014). More recent findings, by contrast, revealed that subjective factors such as adolescents' beliefs about their medication and previous experiences play a more important role than objective benefits and risks of the medication (Niemeyer et al., 2018). Therefore, subjective attitudes should be investigated in more detail (Häge et al., 2018). Ferrin et al. (2012), for instance, developed a self-rating and parentrating questionnaire to identify adolescents' underlying attitudes concerning ADHD medication. While such questionnaires may be useful for clinicians to gain a deeper understanding of which factors might influence (non)adherence in their patients, it has not yet been adequately investigated whether parents are capable of correctly assessing the attitudes and beliefs of their offspring in this respect.

To date, there are no established validated intervention programs to improve medication adherence in adolescents with mental diseases (Buitelaar, 2017). Moreover, it remains unclear whether (preventive) interventions for all patients represent a useful approach, or whether such interventions should rather focus on subgroups with a greater risk of low adherence. For instance, patients with symptoms of anxiety or with a lower educational level factors that could contribute to reservations and irrational health beliefs - might be at higher risk of nonadherence to medication and therefore in need of corresponding therapeutic attention. Research in this regard is limited in our field (for an overview, see Häge et al., 2018), but there are numerous studies from other fields of medicine suggesting that different factors such as female sex, multimorbidity, or low educational background might be linked to low medication adherence, and that such demographic and socioeconomic factors could be useful for identifying and paying special attention to subgroups at high risk of nonadherence (Manteuffel et al., 2014; Rolnick et al., 2013).

Based on the current state of evidence, the SEMA study (Subjective Experience and Medication Adherence in Adolescents with Psychiatric Disorders) was conducted to investigate the subjective experience of adolescents with psychiatric disorders, their attitudes towards medication and related factors, and the association with medication adherence (Mechler \& Häge, 2019; Niemeyer et al., 2018).

As part of the SEMA study, the present work addresses the following research questions:

1. What is the proportion of incomplete medication adherence among this study population of adolescents with psychiatric disorders?

2. Are aspects such as demographic, clinical, and socioeconomic factors associated with incomplete medication adherence in this cohort?

3. To what extent do parent and patient assessments correspond regarding adolescents' attitudes toward medication treatment? 


\section{Methods}

Here, we present analyses of data derived from the multicenter SEMA study.

Participants were recruited from the Department of Child and Adolescent Psychiatry and Psychotherapy at the Central Institute of Mental Health in Mannheim, the AWO (Arbeiterwohlfahrt; Workers' Welfare Association) Psychiatric Center in Königslutter am Elm and connected outpatient clinics in Wolfsburg and Braunschweig, as well as from the Department for Child and Adolescent Psychiatry and Psychotherapy at the Klinikum am Weissenhof in Weinsberg (all in Germany).

The Ethics Committee II of the Medical Faculty Mannheim, University of Heidelberg, approved the study protocol in May 2014.

Data were collected from September 2014 to December 2019.

\section{Study Population}

Inclusion criteria were: (1) age between $12 ; 0$ and $<18 ; 0$ years, (2) prescription of psychotropic medication for the treatment of a psychiatric disorder for at least 2 weeks at the time of inclusion, and (3) a general medical condition allowing for participation. Both outpatients and inpatients were included. Patients and their parents/legal guardians received informed assent/consent forms explaining the study and its potential benefits and risks. Assent/consent forms were signed before participation in the study.

\section{Assessments}

The following assessments were performed:

- The self-/patient-rated Medication Adherence Rating Scale (MARS; Thompson et al., 2000): The MARS was developed to assess medication adherence in psychiatric patients. It includes 10 dichotomous questions, with a higher number of positively rated items corresponding to a higher level of nonadherence.

- The patient- and parent-rated versions of the Questionnaire on Attitudes Toward Treatment (QATT; Ferrin et al., 2012): The patient/adolescent version of the QATT comprises 65 items covering the main dimensions "preoccupations," "insight," and "self-concept". The parent version comprises 65 items covering the main dimensions "child's personal attitudes," "worries," "social stigma," "insight," "future side effects," and "knowledge" (for details, see also Ferrin et al., 2012). The two versions include five identical items assessing the adolescents' subjective attitudes toward treatment (see Table 1), rated on a 5-point Likert scale ranging from 1 (always false) to 5 (always true). The original English-language QATT instrument was carefully translated into German and backtranslated by academic professionals (see ESM 1 and ESM 2).

Additionally, we collected demographic, clinical, and socioeconomic data including sex, age, treatment setting (inpatient vs. outpatient), main diagnosis, comorbidities and symptoms, current and previous medication and comedication, patient's and parents' educational level, and parents' profession.

\section{Definition}

Following the same approach as in Niemeyer et al. (2018), the classification of patients' medication adherence was based on the MARS and the patient version of the QATT. Patients who fulfilled at least one of the following criteria were classified as not completely adherent:

- positive findings in the MARS (two or more positive items out of four);

- having discontinued a previous treatment of the current main disorder of their own volition (as reported on the patient version of the QATT); or

- not having taken all of their prescribed medication in the week before the investigation (as reported in the patient version of the QATT).

Accordingly, participants who did not fulfill any of these criteria were classified as completely adherent.

\section{Statistical Methods}

Chi-square tests were performed to compare completely adherent and not completely adherent adolescents according to sex, age, inpatient or outpatient status, psychiatric multimorbidity, and polypharmacy. Because of small sample sizes, Fisher's exact tests were used concerning the patient's current school, the parents' educational level, and main diagnosis.

For each of the five QATT items describing the adolescents' subjective attitudes toward treatment (see Table 1), Cohen's Kappa was used to assess the agreement between patient and parent ratings on the 5-point Likert scale. To qualify the consensus, we used the classification from Landis and Koch (1977), with poor $(\kappa \leq 0)$, slight $(0<\kappa \leq 0.2)$, fair $(0.2<\kappa \leq 0.4)$, moderate $(0.4<\kappa \leq 0.6)$, substantial $(0.6<\kappa \leq 0.8)$, and (almost) perfect $(0.8<\kappa \leq 1)$ consensus. Additionally, the patient-parent consensus was analyzed in the same way in subgroups concerning demographic, 
socioeconomic, and clinical characteristics (sex, age, inpatient or outpatient, school, parents' educational level, main diagnosis, psychiatric multimorbidity, polypharmacy, adherence).

Furthermore, we determined the differences between patient and parent ratings of the five QATT items. The absolute values of these differences were calculated and added up, forming an overall measure of consensus between adolescent and parent ratings. Mann-Whitney $U$ tests and Kruskal-Wallis tests were applied to examine group differences in this overall measure of consensus regarding demographic, socioeconomic, and clinical characteristics. Statistical significance was set at $p<.05$ (two-sided) for all tests. All statistical analyses were conducted using SPSS (IBM SPSS Statistics 27.0.1).

\section{Results}

\section{Study Population}

In total, $N=75$ adolescents were included in the study; $n=$ $43(57.3 \%)$ participants were female and $n=32(42.7 \%)$ were male; $n=56(74.7 \%)$ were inpatients and $n=19$ (25.3\%) were outpatients. The adolescents' ages ranged from $12 ; 0$ to $17 ; 11$ years, with an average age of 15.4 years.

The seven most common main diagnoses were affective disorders $(n=34)$, externalizing disorders (e.g., ADHD) $(n=11)$, anxiety disorders $(n=7)$, obsessive-compulsive disorder $(n=7)$, eating disorders $(n=5)$, schizophrenia $(n=$ $5)$ and posttraumatic stress disorder $(n=3) ; n=35$ (46.7\%) adolescents had at least one psychiatric comorbidity.

$n=52(69.3 \%)$ adolescents were prescribed one psychopharmaceutical agent and $n=23(30.7 \%)$ more than one. The most common psychotropic medications were SSRIs (selective serotonin reuptake inhibitors) $(n=45)$, atypical antipsychotics $(n=22)$, psychostimulants $(n=14)$, and other antidepressant agents $(n=11)$.

\section{(1) Adherence}

All $N=75$ adolescents completed the QATT and the MARS instrument, and $n=48$ parents completed the parent version of the QATT. According to the definition provided above, $n=45(60 \%)$ adolescents were classified as completely adherent and $n=30(40 \%)$ as not completely adherent. In the group of not completely adherent participants, $n=$ 20 had not taken all of their prescribed pills in the week before participation, $n=12$ had discontinued a previous treatment of their own volition, and $n=13$ participants had two or more positively rated items on the MARS.

\section{(2) Potential Predictors of Adherence}

Of the group of patients receiving one medication, a significantly higher proportion was classified as completely adherent compared to those receiving multiple medications. There were no statistically significant differences between completely and not completely adherent adolescents concerning age, sex, inpatient or outpatient status, main diagnosis, psychiatric multimorbidity, or socioeconomic variables (for more details see Table 2).

\section{(3) Consensus Between Participants and Parents}

Overall, the consensus between patients and parents $(n=$ 48 patient-parent dyads) with respect to the five investigated QATT items ranged from slight $(\kappa=0.157)$ to fair $(\kappa=$ 0.205) (see Table 3). Parent ratings of their child's attitudes differed from adolescents' self-ratings in both directions. Relatively speaking, the strongest consensus was found for item 7 ("Child prefers only one pill") with $\kappa=$ 0.205 , while the weakest consensus was found for item 9 ("Child is happy with functioning at school"), with $\kappa=$ 0.157 (see Table 3).

Moderate levels of consensus $(\kappa=0.4-0.5)$ were only found for single items in subgroups (for details, see Table 3): The consensus between patients and parents was moderate on item 7 if patients had attended a lower-track secondary school of the German tripartite system (Hauptschule), on item 8 ("Child is happy with the way he or she

Table 1. QATT items of "child's personal attitudes"

\begin{tabular}{lll}
\hline QATT item & Patient version & Parent version \\
\hline 7 & I prefer to take only one pill a day (rather than many pills). & My child prefers taking only one pill a day (rather than many pills a day). \\
8 & I am happy with the way I am. & My child is happy with the way he or she is. \\
9 & I am happy with how I am doing at school (or at work). & My child is happy with how he or she is doing at school. \\
14 & I take this medication against my will. & My child takes medication against his or her will. \\
22 & I am ready to follow this treatment. & My child is motivated and ready to follow a treatment.
\end{tabular}

Notes: Items were rated on a Likert scale with 1 (always false), 2 (mostly false), 3 (not sure), 4 (mostly true), and 5 (always true). Abbreviation: QATT - Questionnaire on Attitudes Toward Treatment (Ferrin et al., 2012). 
Table 2. Group comparisons, demographic and socioeconomic characteristics

\begin{tabular}{|c|c|c|c|}
\hline & $\begin{array}{l}\text { Completely adherent; } \\
\mathrm{n}(\%)\end{array}$ & $\begin{array}{l}\text { Not completely } \\
\text { adherent; } \mathrm{n}(\%)\end{array}$ & $p$-value \\
\hline Total & $45(60.0)$ & $30(40.0)$ & \\
\hline Treatment setting & & & .828 \\
\hline Inpatient & $34(60.7)$ & $22(39.3)$ & \\
\hline Outpatient & $11(57.9)$ & $8(42.1)$ & \\
\hline Sex & & & .567 \\
\hline Female & $27(62.8)$ & $16(37.2)$ & \\
\hline Male & $18(56.3)$ & $14(43.8)$ & \\
\hline Age group & & & .659 \\
\hline Age $12 ; 0$ to $14 ; 11$ years & $10(55.6)$ & $8(44.4)$ & \\
\hline Age $15 ; 0$ to $17 ; 11$ years & $35(61.4)$ & $22(38.6)$ & \\
\hline Patient's current school & & & .782 \\
\hline Lower-track secondary school (Hauptschule) & $5(45.5)$ & $6(54.5)$ & \\
\hline Medium-track secondary school (Realschule) & $17(60.7)$ & $11(39.3)$ & \\
\hline Higher-track secondary school (Gymnasium) & $21(65.6)$ & $11(34.4)$ & \\
\hline Special school (Förderschule) & $2(50.0)$ & $2(50.0)$ & \\
\hline Educational level of father & & & .807 \\
\hline Father with lower-track secondary school certificate (Hauptschulabschluss) & $8(57.1)$ & $6(42.9)$ & \\
\hline Father with medium-track secondary school certificate (Mittlere Reife) & $11(61.1)$ & $7(38.9)$ & \\
\hline Father with higher-track secondary school certificate (Abitur) & $16(57.1)$ & $12(42.9)$ & \\
\hline Educational level of mother & & & .591 \\
\hline Mother with lower-track secondary school certificate (Hauptschulabschluss) & $6(60.0)$ & $4(40.0)$ & \\
\hline Mother with medium-track secondary school certificate (Mittlere Reife) & $17(63.0)$ & $10(37.0)$ & \\
\hline Mother with higher-track secondary school certificate (Abitur) & $13(50.0)$ & $13(50.0)$ & \\
\hline Main diagnosis & & & .956 \\
\hline Externalizing disorder & $5(45.5)$ & $6(54.5)$ & \\
\hline Eating disorder & $3(60.0)$ & $2(40.0)$ & \\
\hline Reactive attachment disorder & $1(100.0)$ & $0(0.0)$ & \\
\hline Mood disorder & $20(58.8)$ & $14(41.2)$ & \\
\hline Pervasive developmental disorder & $0(0.0)$ & $1(100)$ & \\
\hline Anxiety disorder & $5(71.4)$ & $2(28.6)$ & \\
\hline Schizophrenia & $3(60.0)$ & $2(40.0)$ & \\
\hline Post-traumatic stress disorder & $2(66.7)$ & $1(33.3)$ & \\
\hline Personality disorder & $1(100.0)$ & $0(0.0)$ & \\
\hline Obsessive disorder & $5(71.4)$ & $2(28.6)$ & \\
\hline Psychiatric multimorbidity & & & .637 \\
\hline One psychiatric disorder & $25(62.5)$ & $15(37.5)$ & \\
\hline Multiple psychiatric disorders & $20(57.1)$ & $15(42.9)$ & \\
\hline Polypharmacy & & & .014 \\
\hline One psychotropic medication prescribed & $36(69.2)$ & $16(30.8)$ & \\
\hline Multiple psychotropic medications prescribed & $9(39.1)$ & $14(60.1)$ & \\
\hline
\end{tabular}

Note: Chi-square tests and for small samples Fisher's exact tests (two-sided). 
is") if the mother had received a lower-track secondary school certificate (Hauptschulabschluss), and on item 22 ("Child is motivated to follow treatment") if patients had attended a medium-track secondary school (Realschule).
The analyses of the overall measure of consensus revealed no statistically significant differences between groups formed according to sociodemographic and clinical characteristics (sex, age, inpatient or outpatient status,

Table 3. Cohen's Kappa as measure for the consensus of patients and parents in answering single QATT items according to demographic, clinical, and socioeconomic characteristics

\begin{tabular}{|c|c|c|c|c|c|c|}
\hline & 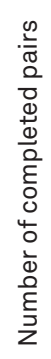 & 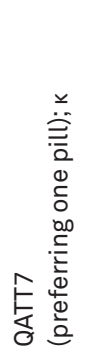 & 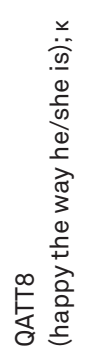 & 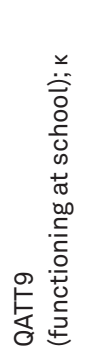 & 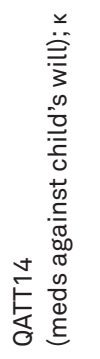 & 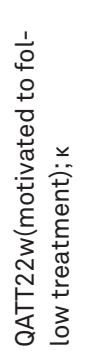 \\
\hline Total & 48 & $0.21 *$ & $0.17 *$ & $0.16^{*}$ & $0.18^{*}$ & $0.20 *$ \\
\hline Inpatient & 35 & $0.18 *$ & $0.20 *$ & 0.12 & $0.18 *$ & 0.12 \\
\hline Outpatient & 13 & 0.22 & 0.03 & $0.25 *$ & 0.11 & $0.37 *$ \\
\hline Female & 27 & 0.15 & 0.05 & $0.33^{*}$ & $0.24^{*}$ & $0.25^{\star}$ \\
\hline Male & 21 & $0.28 *$ & $0.31 *$ & -0.07 & 0.10 & 0.10 \\
\hline Age 12 to 14 & 12 & 0.06 & 0.09 & 0.04 & 0.09 & $0.22 *$ \\
\hline Age 15 to 17 & 36 & $0.24^{\star}$ & $0.18^{*}$ & $0.10 *$ & $0.20 *$ & 0.22 \\
\hline Lower-track secondary school (Hauptschule) & 7 & $0.42 *$ & 0.24 & 0.05 & $0.32 *$ & -0.03 \\
\hline Medium-track secondary school (Realschule) & 15 & $0.33^{*}$ & $0.30 *$ & 0.23 & 0.06 & $0.44^{*}$ \\
\hline Higher-track secondary school (Gymnasium) & 23 & 0.03 & 0.07 & 0.05 & $0.22 *$ & 0.13 \\
\hline Father with lower-track secondary school certificate (Hauptschulabschluss) & 10 & 0.22 & -0.07 & -0.02 & 0.13 & 0.06 \\
\hline Father with medium-track secondary school certificate (Mittlere Reife) & 10 & $0.32 *$ & 0.27 & 0.14 & 0.21 & 0.32 \\
\hline Father with higher-track secondary school certificate (Abitur) & 18 & $0.25 *$ & $0.20 *$ & $0.24^{\star}$ & 0.14 & 0.21 \\
\hline Mother with lower-track secondary school certificate (Hauptschulabschluss) & 6 & -0.03 & $0.50 *$ & 0.14 & 0.23 & -0.26 \\
\hline Mother with medium-track secondary school certificate (Mittlere Reife) & 19 & $0.30 *$ & 0.09 & 0.20 & 0.18 & 0.24 \\
\hline Mother with higher-track secondary school certificate (Abitur) & 14 & 0.09 & $0.27 *$ & 0.09 & 0.20 & $0.35 *$ \\
\hline Externalizing disorder & 8 & 0.16 & -0.14 & -0.06 & 0.09 & 0.20 \\
\hline Mood disorder & 21 & 0.11 & $0.25 *$ & 0.18 & 0.14 & 0.06 \\
\hline Obsessive disorder & 6 & 0.14 & -0.03 & $0.50 *$ & 0.20 & $0.40 *$ \\
\hline One psychiatric disorder & 26 & 0.18 & 0.18 & 0.18 & 0.08 & $0.25 *$ \\
\hline Multiple psychiatric disorders & 22 & $0.22 *$ & 0.17 & 0.15 & $0.30 *$ & 0.16 \\
\hline One psychotropic medication prescribed & 16 & $0.23 *$ & 0.15 & $0.21 *$ & $0.15 *$ & $0.34 *$ \\
\hline Multiple psychotropic medications prescribed & 32 & 0.09 & 0.18 & 0.07 & $0.25^{*}$ & -0.10 \\
\hline Completely adherent & 32 & 0.15 & 0.08 & $0.19 *$ & 0.08 & $0.31 *$ \\
\hline Not completely adherent & 16 & $0.23 *$ & $0.33 *$ & 0.10 & $0.39 *$ & 0.01 \\
\hline
\end{tabular}

Note: $N=48$ pairs of patient and parent QATT versions were completed and used for these analyses. Results displayed for subgroups with $n>5$ completed QATT pairs. Abbreviations: QATT - Questionnaire on Attitudes Toward Treatment (Ferrin et al., 2012). * - significant result for kappa; according to Landis and Koch (1977) slight $(0<\kappa \leq 0.2)$, fair $(0.2<\kappa \leq 0.4)$, moderate $(0.4<\kappa \leq 0.8)$ consensus. 
current type of school, educational level of father or mother, main diagnosis psychiatric multimorbidity or polypharmacy).

\section{Discussion}

The present study identified $60 \%$ of participating adolescents with mental disorders as completely adherent to their medication treatment, according to a definition based on information provided in two patient-rated questionnaires. Conversely, $40 \%$ of the participants in this study sample were classified as not completely adherent, suggesting that the risk of failing to adhere to medication treatment is common within the group of adolescents. Our results correspond to previous studies (applying varying definitions), which reported rates of psychotropic medication adherence between $38 \%$ and $96 \%$ in this age group (Häge et al., 2018). Taking into account the potentially severe consequences of an inadequate or insufficient treatment, such as higher rates of morbidity and mortality, worse health outcomes, and poorer quality of life (Novick et al., 2010; Taddeo et al., 2008), it seems essential to gain a deeper understanding of this phenomenon by identifying factors associated with both adherence and nonadherence in adolescents. Such findings could inform the development of tools, interventions, and preventive programs to improve adherence in this particularly vulnerable age group.

Concerning the question of potential predictors of adherence, we found a statistically significant association between medication adherence and the number of prescribed medications with a higher proportion of patients receiving monotherapy classified as completely adherent than those receiving a combination of different medications. This finding may suggest that simple treatment regimens are preferable in terms of adherence. However, it remains unclear whether the association between medication adherence and polypharmacy is directly causal or potentially related to other (co-)factors (e.g., severity of symptoms, adverse events). We found no significant association between medication adherence and other demographic, socioeconomic, or clinical characteristics. In this respect, our results are in line with those of Timlin et al. (2015), who performed a systematic review of factors influencing adherence to medication regimes and nonpharmacological treatments in adolescents in psychiatric care. They found the adolescent's or family's life situation and social environment - including different socioeconomic, demographic, and social-environmental factors - to be unrelated to treatment adherence. Moreover, the latter authors only reported a small number of individual studies with contradictory results. DelBello et al. (2007), for ex- ample, reported an association between medication nonadherence and low socioeconomic status in a sample of 71 adolescents with bipolar disorder; Schimmelmann et al. (2006) found that adolescents with first-episode psychosis showed less adherent behavior when they were living without their family during treatment; and Woldu et al. (2011) reported that adolescents who were adherent to an antidepressant treatment were significantly older than those who were nonadherent. However, because these studies focused on specific psychiatric disorders and/or specific pharmaceutical interventions, the comparability of their results with findings from studies following a broader approach, such as the SEMA study, are limited.

In summary, it now seems that clinicians need to generally consider adolescents with mental disorders to be potentially at risk of (medication) nonadherence regardless of demographic or socioeconomic aspects.

A further important finding of our analysis was that parents' and adolescents' assessments of the adolescents' attitudes toward treatment tended to differ: In two out of five investigated QATT items addressing adolescents' subjective attitudes, the consensus between adolescents and parents was observed as fair, with the other three items showing only a slight consensus. In some subgroups, such as patients with obsessive-compulsive disorder, patients with schizophrenia, or patients attending a lower-track secondary school (Hauptschule), single items revealed a better patient-parent consensus, but this was not universal for all items within these subgroups.

Our results are in accordance with studies comparing parent proxy ratings with child self-ratings concerning other subjective aspects, which also found interrater discrepancies between parents and their children to be common (Galloway \& Newman, 2017; Klassen et al., 2006; Plück et al., 1997). For instance, studies investigating the quality of life in children with mental disorders found that parents often assess their children's attitudes and beliefs differently than the children themselves, especially when questioned about psychosocial circumstances like school and social and emotional experiences (Galloway \& Newman, 2017; Lee et al., 2019). Other examples include a study that found low interrater agreement between parents and their adolescent children on behavioral executive function measures or ADHD symptoms (Krieger et al., 2019).

To our knowledge, the present study is the first to investigate patient-parent consensus in the assessment of adolescents' attitudes toward treatment with psychotropic medication. Our findings showed that parents' assessments of their offspring's attitudes mainly did not correspond with the information provided by the adolescents. Therefore, we recommend that clinicians do not consider parents' assessments as a sufficiently reliable source of information in this regard. 
The findings of this study need to be interpreted in the context of several limitations. First, because the sample could only include adolescents who voluntarily agreed to participate, it seems possible that the rate of adherence is higher in this selected (motivated) group compared to patients in routine clinical practice. Furthermore, it seems possible that therapy conditions and closer monitoring of inpatients influenced patients' adherence, although overall we did not find a statistically significant difference between inpatients and outpatients with regard to adherence in our sample.

Second, to gain a broader understanding of the phenomenon of nonadherence in adolescents, we did not restrict the sample to specific mental disorders. This resulted in a heterogeneous study population with small subgroups, some of which were too small for statistical analyses. In particular, the variation in prescribed medication was too broad to allow for further analysis.

Third, while the QATT was originally developed in the English language to investigate attitudes toward treatment in adolescents with ADHD, we applied a German version of the questionnaire in a sample of adolescents not limited to patients with ADHD but predominantly with other mental disorders. Nevertheless, the findings are comparable to findings in ADHD cohorts (e.g., QATT total scores for adherent/nonadherent patients [not presented here]; Ferrin et al., 2012). It should be noted, however, that the German version of the instrument has not yet been psychometrically validated in the exact form used in the present study.

Fourth, two of the six QATT items used to analyze the correspondence between parent and patient assessments do not assess attitudes toward medication/treatment specifically, but rather attitudes toward satisfaction of the adolescents with themselves and their own (school) performance. Nevertheless, these attitudes are likely to be indirectly relevant for medication adherence.

Fifth, in the present analysis, the measurement and classification of (not) completely adherent was limited to patients' self-ratings using criteria derived from two instruments and did not include third-party assessments or objective approaches.

Finally, it needs to be considered that the time interval between the first prescription of medication and inclusion into the study was defined as at least 2 weeks. It can be assumed that attitudes and adherence of patients change over the course of a longer treatment period, beyond the time interval observed. Unfortunately, this aspect could not be investigated within the context of this study. Follow-up investigations would be helpful in this regard.

Currently, there is a growing interest in the role of subjective factors such as patients' health beliefs, previous experiences and attitudes toward prescribed medication, and the relevance thereof in terms of (non)adherence. Notably, recent findings suggest that such subjective factors appear to be more important for real-life adherence in adolescents than objective benefits and the side effects of medication (Charach et al., 2014; Niemeyer et al., 2018). In a first analysis of data collected within the SEMA project, we found different parameters of adolescents' subjective experiences, perceptions, and attitudes that characterized the group of adolescents with reduced adherence to psychotropic medication (for details, see Niemeyer et al., 2018). In addition, the results from this second analysis suggest that clinicians should not rely exclusively on parents' assessments to identify adolescent patients' attitudes toward psychotropic medication. Moreover, demographic and socioeconomic characteristics did not appear to be helpful to identify adolescents at risk of nonadherence in this population of individuals treated with psychotropic medication.

\section{Conclusions}

Insufficient medication adherence is a widespread clinical phenomenon in adolescents with psychiatric disorders. Taking into account the consequences of low adherence for this population, it seems essential to identify nonadherent patients in routine clinical care early on. Based on these study findings, the risk of adolescents failing to completely adhere to psychotropic medication treatment seems to be unrelated to demographic and socioeconomic factors, whereas subjective factors such as adolescents' experiences and attitudes toward treatment may play an important role. Moreover, if warranted clinically, simple treatment regimens - including the avoidance of polypharmacy - may be beneficial in terms of medication adherence. Since parents tend to assess their adolescent offspring's attitudes differently, it appears essential to explore the adolescents' own self-reported attitudes in detail. Presumably, insight into adolescents' subjective attitudes will foster our understanding of the multifaceted phenomenon of nonadherence and thus contribute to the development of, for instance, individualized psychoeducational approaches and interventions to improve adherence in this age group.

\section{Electronic Supplementary Material}

The electronic supplementary material (ESM) is available with the online version of the article at https://doi. org/10.1024/1422-4917/a000813

ESM 1. SEMA-STUDIE - QATT-Fragebogen für die Eltern. ESM 2. SEMA-STUDIE - QATT-Fragebogen für Jugendliche. 


\section{References}

Brinkman, W. B., Baum, R., Kelleher, K.J., Peugh, J., Gardner, W., Lichtenstein, P., ... Epstein, J. N. (2016). Relationship between attention-deficit/hyperactivity disorder care and medication continuity. Journal of the American Academy of Child and Adolescent Psychiatry, 55(4), 289-294. https://doi.org/10.1016/j.jaac.2016. 02.001

Buitelaar, J.K. (2017). Optimising treatment strategies for ADHD in adolescence to minimise "lost in transition" to adulthood. Epidemiology and Psychiatric Sciences, 26(5), 448-452. https://doi. org/10.1017/S2045796017000154

Chapman, S.C., \& Horne, R. (2013). Medication nonadherence and psychiatry. Current Opinion in Psychiatry, 26(5), 446-452. https://doi.org/10.1097/YC0.0b013e3283642da4

Charach, A., \& Fernandez, R. (2013). Enhancing ADHD medication adherence: Challenges and opportunities. Current Psychiatry Reports, 15(7), 371. https://doi.org/10.1007/s11920-013-0371-6

Charach, A., Yeung, E., Volpe, T., Goodale, T., \& Dosreis, S. (2014). Exploring stimulant treatment in ADHD: Narratives of young adolescents and their parents. BMC Psychiatry, 14, 110. https:// doi.org/10.1186/1471-244x-14-110

Christie, D., \& Viner, R. (2005). Adolescent development. British Medical Journal, 330(7486), 301-304. https://doi.org/10.1136/ British Medical Journal.330.7486.301

DelBello, M.P., Hanseman, D., Adler, C.M., Fleck, D. E., \& Strakowski, S.M. (2007). Twelve-month outcome of adolescents with bipolar disorder following first hospitalization for a manic or mixed episode. American Journal of Psychiatry, 164(4), 582-590. https://doi.org/10.1176/ajp.2007.164.4.582

Ferrin, M., Ruiz-Veguilla, M., Blanc-Betes, M., Abd, S. E., Lax-Pericall, T., Sinclair, M., \& Taylor, E. (2012). Evaluation of attitudes toward treatment in adolescents with attention deficit hyperactivity disorder (ADHD). European Child and Adolescent Psychiatry, 21(7), 387-401. https://doi.org/10.1007/s00787-012-0 277-6

Franke, C., Fegert, J.M., Kruger, U., \& Kolch, M. (2016). [Prescriptions of psychotropic drugs to children and adolescents in Germany]. Zeitschrift für Kinder- und Jugendpsychiatrie und Psychotherapie, 44(4), 259-274. https://doi. org/10.1024/1422-4917/a000417

Gajria, K., Lu, M., Sikirica, V., Greven, P., Zhong, Y., Qin, P., \& Xie, J. (2014). Adherence, persistence, and medication discontinuation in patients with attention-deficit/hyperactivity disorder: A systematic literature review. Neuropsychiatric Disease and Treatment, 10, 1543-1569. https://doi.org/10.2147/ndt.s65721

Galloway, H., \& Newman, E. (2017). Is there a difference between child self-ratings and parent proxy-ratings of the quality of life of children with a diagnosis of attention-deficit hyperactivity disorder (ADHD)? A systematic review of the literature. Attention Deficit and Hyperactivity Disorders, 9(1), 11-29. https://doi. org/10.1007/s12402-016-0210-9

Häge, A., Weymann, L., Bliznak, L., Marker, V., Mechler, K., \& Dittmann, R.W. (2018). Non-adherence to psychotropic medication among adolescents: A systematic review of the literature. Zeitschrift für Kinder- und Jugendpsychiatrie und Psychotherapie, 46(1), 69-78. https://doi.org/10.1024/1422-4917/a000505

Hsia, Y., \& Maclennan, K. (2009). Rise in psychotropic drug prescribing in children and adolescents during 1992-2001: A population-based study in the UK. European Journal of Epidemiology, 24(4), 211-216. https://doi.org/10.1007/s10654-00 9-9321-3

Kessler, R.C., Amminger, G.P., Aguilar-Gaxiola, S., Alonso, J., Lee, S., \& Ustün, T.B. (2007). Age of onset of mental disorders: A review of recent literature. Current Opinion in Psychiatry, 20(4), 359-364. https://doi.org/10.1097/YC0.0b013e32816ebc8c
Klassen, A. F., Miller, A., \& Fine, S. (2006). Agreement between parent and child report of quality of life in children with attentiondeficit/hyperactivity disorder. Child: Care, Health and Development, 32(4), 397-406. https://doi.org/10.1111/j.1365-2214.2 006.00609.x

Kovess, V., Choppin, S., Gao, F., Pivette, M., Husky, M., \& Leray, E. (2015). Psychotropic medication use in French children and adolescents. Journal of Child and Adolescent Psychopharmacology, 25(2), 168-175. https://doi.org/10.1089/cap.2014.0058

Krieger, V., Amador-Campos, J.A., \& Peró-Cebollero, M. (2019). Interrater agreement on behavioral executive function measures in adolescents with attention deficit hyperactivity disorder. International Journal of Clinical and Health Psychology, 19(2), 141-149. https://doi.org/10.1016/j.ijchp.2019.02.007

Landis, J.R., \& Koch, G.G. (1977). The measurement of observer agreement for categorical data. Biometrics, 159-174.

Lee, Y.C., Yang, H.J., Lee, W.T., \& Teng, M.J. (2019). Do parents and children agree on rating a child's HRQOL? A systematic review and Meta-analysis of comparisons between children with attention deficit hyperactivity disorder and children with typical development using the PedsQL(TM). Disability and Rehabilitation, 41(3), 265-275. https://doi.org/10.1080/09638288.2017.1391338

Lopez-Leon, S., Lopez-Gomez, M.I., Warner, B., \& Ruiter-Lopez, L. (2018). Psychotropic medication in children and adolescents in the United States in the year 2004 vs 2014. Daru, 26(1), 5-10. https://doi.org/10.1007/s40199-018-0204-6

Manteuffel, M., Williams, S., Chen, W., Verbrugge, R.R., Pittman, D.G., \& Steinkellner, A. (2014). Influence of patient sex and gender on medication use, adherence, and prescribing alignment with guidelines. Journal of Women's Health (Larchmt), 23(2), 112-119. https://doi.org/10.1089/jwh.2012.3972

Mechler, K., \& Häge, A. (2019). “Drugs don't work in patients who don't take them." Zeitschrift für Kinder- und Jugendpsychiatrie und Psychotherapie, 1-5. https://doi.org/10.1024/1422-4917/ a000645

Niemeyer, L., Schumm, L., Mechler, K., Jennen-Steinmetz, C., Dittmann, R. W., \& Häge, A. (2018). "When I stop my medication, everything goes wrong": Content analysis of interviews with adolescent patients treated with psychotropic medication. Journal of Child and Adolescent Psychopharmacology, 28(9), 655-662. https://doi.org/10.1089/cap.2018.0072

Novick, D., Haro, J.M., Suarez, D., Perez, V., Dittmann, R.W., \& Haddad, P.M. (2010). Predictors and clinical consequences of non-adherence with antipsychotic medication in the outpatient treatment of schizophrenia. Psychiatry Research, 176(2-3), 109-113. https://doi.org/10.1016/j.psychres.2009.05.004

Piovani, D., Clavenna, A., \& Bonati, M. (2019). Prescription prevalence of psychotropic drugs in children and adolescents: An analysis of international data. European Journal of Clinical Pharmacology, 75(10), 1333-1346. https://doi.org/10.1007/ s00228-019-02711-3

Plück, J., Döpfner, M., Berner, W., Fegert, J. M., Huss, M., Lenz, K., ... Lehmkuhl, G. (1997). [The value of different sources of information in evaluating psychiatric disorders in adolescence--a comparison of parental judgment and self-assessment by adolescents]. Praxis der Kinderpsychologie und Kinderpsychiatrie, 46(8), 566-582.

Rolnick, S.J., Pawloski, P.A., Hedblom, B.D., Asche, S. E., \& Bruzek, R.J. (2013). Patient characteristics associated with medication adherence. Clinical Medicine \& Research, 11(2), 54-65. https:// doi.org/10.3121/cmr.2013.1113

Schimmelmann, B.G., Conus, P., Schacht, M., McGorry, P., \& Lambert, M. (2006). Predictors of service disengagement in firstadmitted adolescents with psychosis. Journal of the American Academy of Child and Adolescent Psychiatry, 45(8), 990-999. https://doi.org/10.1097/01.chi.0000223015.29530.65 
Skaer, T.L., Sclar, D.A., \& Robison, L.M. (2009). Trends in prescriptions for antidepressant pharmacotherapy among US children and adolescents diagnosed with depression, 1990 through 2001: An assessment of accordance with treatment recommendations from the American Academy of Child and Adolescent Psychiatry. Clinical Therapeutics, 31 Pt 1, 1478-1487. https://doi.org/10.1016/j.clinthera.2009.07.002

Sun, S.X., Liu, G.G., Christensen, D. B., \& Fu, A.Z. (2007). Review and analysis of hospitalization costs associated with antipsychotic nonadherence in the treatment of schizophrenia in the United States. Current Medical Research and Opinion, 23(10), 23052312. https://doi.org/10.1185/030079907×226050

Taddeo, D., Egedy, M., \& Frappier, J.Y. (2008). Adherence to treatment in adolescents. Paediatrics \& Child Health, 13(1), 19-24. https://doi.org/10.1093/pch/13.1.19

Thompson, K., Kulkarni, J., \& Sergejew, A.A. (2000). Reliability and validity of a new Medication Adherence Rating Scale (MARS) for the psychoses. Schizophrenia Research, 42(3), 241-247. https:// doi.org/10.1016/s0920-9964(99)00130-9

Timlin, U., Hakko, H., Heino, R., \& Kyngäs, H. (2015). Factors that affect adolescent adherence to mental health and psychiatric treatment: A systematic integrative review of the literature. Scandinavian Journal of Child and Adolescent Psychiatry and Psychology, 3, 99-107. https://doi.org/10.21307/sjcapp-20 15-010

Woldu, H., Porta, G., Goldstein, T., Sakolsky, D., Perel, J., Emslie, G., ... Brent, D. (2011). Pharmacokinetically and clinician-determined adherence to an antidepressant regimen and clinical outcome in the TORDIA Trial. Journal of the American Academy of Child and Adolescent Psychiatry, 50(5), 490-498. https://doi. org/10.1016/j.jaac.2011.01.018

\section{History}

Manuscript submitted: 28.02.2021

Accepted after revision: 19.05.2021

Published online: 09.07.2021

\section{Conflicts of interests}

Konstantin Mechler was involved as an investigator in clinical trials by Shire, Otsuka, Sunovion, Servier, Lundbeck, Takeda, Nuvelution, Gedeon Richter, and Emalex.

Sarah Hohmann was involved as an investigator in a clinical trial by Servier.

Ralf W. Dittmann received compensation for serving as a consultant or speaker, or he or the institution for which he works received research support or royalties from the organizations or companies indicated: EU (FP7 Programme), U.S. National Institute of Mental Health (NIMH), German Federal Ministry of Health/Regulatory Agency (BMG/BfArM), German Federal Ministry of Education and Research (BMBF), German Research Foundation (DFG), and Volkswagen Foundation; Boehringer Ingelheim, Ferring, Janssen-Cilag, Lilly, Lundbeck, Otsuka, Servier, Shire, Sunovion/Takeda, and Theravance. Ralf W. Dittmann owns Eli Lilly stock. Alexander Häge received conference support, speaker's fees, and/or served in an advisory role for Shire/Takeda and Lilly. He was involved as an investigator in clinical trials by Shire, Takeda, Janssen-Cilag, Otsuka, Sunovion, Servier, Lundbeck, Nuvelution, Gedeon Richter, and Emalex.

All other authors report no potential conflicts of interest.

\section{Funding}

Open access publication enabled by Central Institute of Mental Health (CIMH), Mannheim

\section{Dr. Alexander Häge}

Department of Child and Adolescent Psychiatry and Psychotherapy

Central Institute of Mental Health (CIMH)

J5, 68159 Mannheim

Germany

alexander.haege@zi-mannheim.de 


\section{Frage: Welche Aussage zu Medikamenten-Adhärenz} bei Kindern und Jugendlichen mit psychischen Störungen trifft am wenigsten zu?

a. Mangelnde Adhärenz ist insbesondere bei Jugendlichen ein häufiges Phänomen.

b. Mangelnde Adhärenz trägt wesentlich zur Persistenz von psychischen Symptomen bei.

c. Nebenwirkungen und unzureichende Wirkung einer Substanz können Nicht-Adhärenz begünstigen.

d. Subjektive Einstellung von Jugendlichen spielen für die Adhärenz eine besonders bedeutende Rolle.

e. Sozioökonomische Faktoren sind hilfreich, um Risikogruppen für Nicht-Adhärenz zu identifizieren.

2. Frage: Welche Aussage zum „Questionnaire on Attitudes Towards Treatment" (QATT) trifft am wenigsten zu?

a. Der QATT dient der Erfassung subjektiver Einstellungen von Patienten zur Psychopharmakotherapie.

b. Der QATT beinhaltet 65 Items und ist in verschiedene Domänen unterteilt.

c. Der QATT wurde ursprünglich für Patienten mit ADHS entwickelt.

d. Der QATT ist für Kinder, nicht aber für Jugendliche geeignet.

e. Der QATT ist in einer Patienten- und in einer Elternversion erhältlich.

\section{Frage: Welche Aussage zur „Medication Adherence} Rating Scale" (MARS) trifft am ehesten zu?

a. Die MARS ist ein Fragebogen, bestehend aus 40 Fragen, unterteilt in drei verschiedene Domänen.

b. Die MARS dient der Erfassung subjektiver Einstellungen von Patienten zur Psychopharmakotherapie.

c. Die MARS wurde ursprünglich für Patienten mit Diabetes Mellitus entwickelt.

d. Eine höhere Anzahl positiver Items in der MARS entspricht einer geringeren Adhärenz.

e. Die MARS stellt ein objektives Maß der Adhärenz-Erfassung dar.
4. Frage: Welche Aussage trifft am ehesten zu? Ergebnisse der SEMA Studie deuten darauf hin, dass sich im Hinblick auf die Einnahme von Psychopharmaka...

a. ...Mädchen häufiger adhärent verhalten als Jungen.

b. ...Gymnasiasten häufiger adhärent verhalten als Realund Hauptschüler.

c. ...Patienten, deren Mütter einen höheren Schulabschluss haben, häufiger adhärent verhalten.

d....Patienten, deren Väter einen höheren Schulabschluss haben, häufiger adhärent verhalten.

e. ...Patienten, die mehrere Psychopharmaka verschrieben bekommen, seltener adhärent verhalten.

\section{Frage: Subjektive Einstellungen von Jugendlichen} zu einer Pharmakotherapie wurden im Rahmen der SEMA-Studie durch Befragen von Jugendlichen und deren Eltern ermittelt. Welche der folgenden Aussagen zum Vergleich von Jugendlichen- und Elternaussagen trifft am ehesten zu: Die Übereinstimmung der Aussagen von Jugendlichen und deren Eltern war...

a.... insgesamt gering.

b. ... bei Eltern mit hohem Bildungsstand hoch.

c. ... bei Eltern mit niedrigem Bildungsstand hoch.

d. ... bei Patienten mit externalisierenden Störungen hoch.

e. ... bei männlichen Patienten hoch. 
Um Ihr CME-Zertifikat zu erhalten (min. drei richtige Antworten), schicken Sie bitte den ausgefüllten Fragebogen mit einem frankierten Rückumschlag bis zum 27.08.2021 an die nebenstehende Adresse. Später eintreffende Antworten und solche ohne bzw. mit nicht frankierten Rückumschlägen können nicht mehr berücksichtigt werden.

\section{Milena Becker}

LWL-Universitätsklinik Hamm der Ruhr-Universität Bochum Klinik für Kinder- und Jugendpsychiatrie, Psychotherapie und Psychosomatik

Heithofer Allee 64

59071 Hamm, Deutschland

\section{Fortbildungszertifikat}

Die Ärztekammer Niedersachsen erkennt hiermit

2 Fortbildungspunkte an.

\section{Stempel}

Kinder- und Jugend-

psychiatrie und

Psychotherapie

04/2021

\section{(\$) hogrefe}

Datum
„Medication Adherence in Adolescents with

Psychiatric Disorders"

Die Antworten bitte deutlich ankreuzen!

a

123

b


45

c

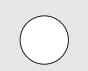

d

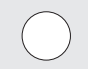

e
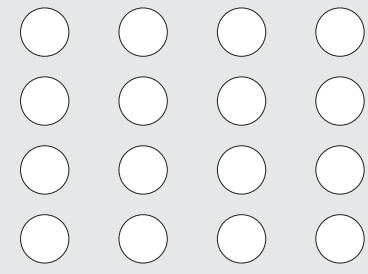

Ich versichere, alle Fragen ohne fremde Hilfe beantwortet zu haben.

Name

Berufsbezeichnung, Titel

Straße, Nr.

PLZ, Ort 